\title{
AUTORES DE VIOLÊNCIA SEXUAL CONTRA CRIANÇAS E ADOLESCENTES: A IMPORTÂNCIA DE INTERVENÇÕES PSICOLÓGICAS
}

\author{
Klindia Ramos Barcelos ${ }^{1}$ \\ Bruna Barcelos Fernandes ${ }^{2}$ \\ Maicon Miranda Marvila ${ }^{3}$ \\ Fabiana Davel Canal ${ }^{4}$ \\ Karen Michel Esber 5
}

Resumo: Atualmente, a violência sexual contra crianças a adolescentes tem sido concebida como uma questão de saúde pública. Trata-se de um tipo de violação aos direitos de crianças e adolescentes, que traz sérias conseqüências, de cunho físico, psicológico e social para suas vítimas. Esse tipo de violência se materializa por meio do abuso e da exploração sexual de crianças e adolescentes. Concebe-se que na violência sexual, existem diversos indivíduos envolvidos, como por exemplo, a vítima e o autor da violência, na qual para enfrentar essa problemática, se faz necessária a adoção do tratamento psicoterapêutico para o autor da violência, uma vez que esse tratamento é capaz de romper com o ciclo da violência e, consequentemente, diminuir os índices de reincidência desse tipo de violação aos direitos previstos no Estatuto da Criança e do Adolescente promulgado em 1990.

Palavras-chave: Violência Sexual; Autores; Intervenções Psicoterapêuticas.

\footnotetext{
1Especialização em Epidemiologia/ Universidade Federal do Espírito Santo, Brasil. E-mail: klindia@hotmail.com. ${ }^{2}$ Especialização em Epidemiologia/ Universidade Federal do Espírito Santo, Brasil. E-mail: bruninhabarcelosf@gmail.com.

${ }^{3}$ Mestrado em Medicina/ Universidade Federal do Rio de Janeiro, Brasil. E-mail: maiconmiranda@outlook.com. ${ }^{4}$ Orientadora: Mestrado em Psicologia Instrucional/ Universidade Federal do Espírito, Brasil. E-mail: fabidavel@yahoo.com.br.

${ }_{5}^{5}$ Orientadora: Doutorado em Sociologia/ Universidade Federal de Goiás, Brasil. E-mail: kesber@hotmail.com.
} 